\title{
Regression of CD30-Positive Large Cell Transformation Arising on Patch-Lesion of Early Mycosis Fungoides
}

\author{
Naoko Kubo ${ }^{1}$, Munenari Itoh ${ }^{1}$, Yoshinori Watanabe ${ }^{1}$, Yoshimasa Nobeyama ${ }^{2}$, and Akihiko \\ Asahina $^{1}$ \\ ${ }^{1}$ Jikei University School of Medicine \\ ${ }^{2}$ The Jikei University School of Medicine
}

June 22, 2020

\begin{abstract}
We present the case of a patient with patch-stage mycosis fungoides who developed ulcerative tumors compatible with large cell transformation. Tumor cells were positive for CD30 and CXCR3 and negative for CCR3, and subsequently exhibited spontaneous regression. Thus, large cell transformation in early mycosis fungoides may not indicate poor prognosis.
\end{abstract}

\section{Regression of CD30-Positive Large Cell Transformation Arising on Patch-Lesion of Early My- cosis Fungoides}

Running head: Regression of Large Cell Transformation in Early Mycosis Fungoides

Naoko Kubo ${ }^{1}$, Munenari Itoh ${ }^{1}$, Yoshinori Watanabe ${ }^{1}$, Yoshimasa Nobeyama ${ }^{1}$ and Akihiko Asahina ${ }^{1}$

1. Department of Dermatology, The Jikei University School of Medicine, Tokyo, Japan

Corresponding author:

Yoshimasa Nobeyama, MD, PhD

Department of Dermatology, The Jikei University School of Medicine

3-25-8 Nishishimbashi, Minato-ku, Tokyo 105-8461, Japan

Tel: +81-3-3433-1111 ext. 3341; Fax: +81-3-5401-0125

E-mail: nobederm@jikei.ac.jp

907 words, 2 tables

Key Words: mycosis fungoides, large cell transformation, early stage, cutaneous T-cell lymphoma, CD30positive lymphoproliferative disorder

\section{Key Clinical Message}

CD30-positive large cell transformation that occurs in early mycosis fungoides potentially possesses characteristics of spontaneous regression as with CD30-positive lymphoproliferative disorders. Such transformation may not relate to poor prognosis.

\section{Introduction}

Mycosis fungoides (MF) is the most common type of cutaneous T-cell lymphoma. Although most MF cases show indolent clinical courses, some cases exhibit severe progression. Previous studies have demonstrated 
that the prognosis for patients with MF depends on several parameters, including age, clinical stage, and specific factors such as large cell transformation (LCT) ${ }^{1-6}$. LCT is diagnosed based on large cells (whether CD30 positive or negative) constituting $>25 \%$ of the infiltrate or forming microscopic nodules within the MF lesion. LCT of MF (MF-LCT) has been observed in 2.3-22.6\% of MF patients during the course of the disease ${ }^{2-11}$. Notably, previous studies reported the development of LCT in 21.3-31.0\% of advanced-stage patients, but in only $1.4 \%$ of early-stage patients ${ }^{3,7}$. Thus, MF-LCT usually is associated with an advanced stage of the disease.

CD30 is a cell membrane protein of the tumor necrosis factor receptor family. CD30 is expressed in activated T-cells and used as a tumor marker. Neoplastic proliferation of CD30+ lymphocytes in the skin is observed in MF-LCT and CD30+ lymphoproliferative disorders (LPDs) such as lymphomatoid papulosis (LyP) and primary cutaneous anaplastic large cell lymphoma (PC-ALCL). Most LyP cases and about 20\% of PC-ALCL cases spontaneously regress with excellent prognoses ${ }^{12-14}$. However, spontaneous regression of MF-LCT has been reported only rarely. Here, we present a case showing spontaneous regression of MF-LCT in patch-stage MF.

\section{Case Report}

A 46-year-old Japanese woman was referred to us with a 2-year history of multiple areas of erythema measuring 1-10 cm in diameter (Fig. 1a, b). The patient had been treated using topical steroids and narrow-band ultraviolet B irradiation for 2 years in another clinic. Peripheral blood tests showed a normal hemogram and a normal range of soluble interleukin-2 receptor; the patient was seronegative for anti-human T-cell leukemia virus type-1 antibody. Histopathological examination revealed that small-sized atypical lymphocyte-like hyperchromatic cells with haloes had infiltrated into the epidermis and upper dermis in a scattered manner (Fig. 1c). Tumor cells were primarily positive for CD4 but negative for CD30. The patient was diagnosed with patch-stage MF. Symptoms were well controlled by topical steroids and narrow-band ultraviolet B irradiation therapy.

Two years later, the patient noticed two rapidly growing tumors located on the MF patch-lesion in the left chest; the tumors had formed necrotic ulcers measuring 2-4 cm in diameter (Fig. 2a). Peripheral blood tests showed a normal hemogram and normal range of soluble interleukin-2 receptor. Imaging examinations revealed no invasion into the viscera. Histopathological examination showed nodular infiltration in the dermis and subcutis with necrotic changes of the epidermis (Fig. 2b). Anaplastic large cells ([?]4 times the size of a small lymphocyte) had formed nodular nests in the dermis and subcutis (Fig. 2c). Small-sized atypical lymphocyte-like cells also had formed nodular nests, primarily in the subcutis (Fig. 2d). Most tumor cells were positive for CD3, CD4, and MIB-1 (Ki-67). Anti-CD30 antibodies were reactive to the anaplastic large cells (Fig. 2e, f), which comprised [?]75\% of the tumor cells, but not to the small-sized atypical lymphocyte-like cells (Fig. 2g). The anaplastic large cells were reactive to antibodies against C-X-C motif chemokine receptor 3 (CXCR3) (Fig. 2h), but not to antibodies against C-C chemokine receptor type 3 (CCR3) (Fig. 2i). Based on these data, a diagnosis of MF-LCT in the patch-stage was made. Three months after their original appearance, the tumors spontaneously regressed, leaving scars (Fig. $2 \mathrm{j}$ ). In the year since, no recurrence has been observed.

\section{Discussion}

The ulcerative tumors occurring in our patient with MF should not be associated with the tumor-stage of typical MF. Typical MF progresses slowly from patch-stage to tumor-stage through plaque-stage over several years, but the tumor lesions in our patient occurred suddenly and grew rapidly. Therefore, the present case is incompatible with the tumor-stage of MF.

The ulcerative tumors that occurred in our patient are compatible with MF-LCT rather than CD30+ LPDs such as PC-ALCL based on the following criteria: i) LCT develops on pre-existing MF lesions, and ii) LCT consists of CD30+ large cells, which comprise [?]75\% of tumor cells, and small-sized atypical lymphocyte-like cells ${ }^{15,16}$. Recently, several studies have distinguished between PC-ALCL and LCT as follows: i) PC-ALCL cells exhibit strong expression of CCR3 and weak expression of CXCR3, while, in contrast, ii) MF cells 
exhibit strong expression of CXCR3 and weak expression of CCR3 ${ }^{17-19}$. In our case, more than $25 \%$ and less than $75 \%$ of the tumor lesions located on patch-lesions consisted of small-sized atypical lymphocyte-like cells and CXCR3-positive, CCR3-negative anaplastic large cells, respectively. Based on these findings, the diagnosis of MF-LCT was confirmed.

Our case shows unique features: LCT occurred in early MF and regressed spontaneously. With regard to LCT in early MF, only two cases (to our knowledge) of CD30+ MF-LCT in the patch-stage have been described previously, with both showing favorable prognoses ${ }^{20,21}$. These cases, in combination with the case reported here, strongly suggest that CD30+ MF-LCT in early MF does not indicate poor prognosis, although MF-LCT occurring in advanced MF has been reported to relate to poor prognosis ${ }^{1,6}$. With regard to spontaneous regression of MF-LCT, there have been only a few case reports ${ }^{22,23}$; notably, PC-ALCL was not definitely excluded in those instances. CD30+ MF-LCT, especially in early MF, also may possess the potential for spontaneous regression like that seen for CD30+ LPDs, including LyP and PC-ALCL. The accumulation of additional such unique cases is expected to contribute to deeper understanding of MF-LCT.

\section{Author Contributions}

Naoko Kubo: This author provided resources.

Munenari Itoh: This author contributed to concertation, validation, and writing.

Yoshinori Watanabe: This author contributed to data curation.

Yoshimasa Nobeyama: This author performed project administration.

Akihiko Asahina: This author provided supervision.

\section{Conflict of Interest Statement}

The authors received no financial support for this study.

The authors have no conflicts of interest to declare.

\section{References}

1 Agar NS, Wedgeworth E, Crichton $\mathrm{S}$ et al. Survival outcomes and prognostic factors in mycosis fungoides/Sezary syndrome: validation of the revised International Society for Cutaneous Lymphomas/European Organisation for Research and Treatment of Cancer staging proposal.J Clin Oncol 2010. 28 : 4730-4739.

2 Lebowitz E, Geller S, Flores E et al. Survival, disease progression and prognostic factors in elderly patients with mycosis fungoides and Sezary syndrome: a retrospective analysis of 174 patients.J Eur Acad Dermatol Venereol 2019. 33 : 108-114.

3 Diamandidou E, Colome-Grimmer M, Fayad L et al. Transformation of mycosis fungoides/Sezary syndrome: clinical characteristics and prognosis. Blood 1998. 92 : 1150-1159.

4 Greer JP, Salhany KE, Cousar JB et al. Clinical features associated with transformation of cerebriform T-cell lymphoma to a large cell process. Hematol Oncol 1990. 8 : 215-227.

5 Barberio E, Thomas L, Skowron F et al. Transformed mycosis fungoides: clinicopathological features and outcome. Br J Dermatol 2007. 157 : 284-289.

6 Scarisbrick JJ, Prince HM, Vermeer MH et al. Cutaneous Lymphoma International Consortium Study of Outcome in Advanced Stages of Mycosis Fungoides and Sezary Syndrome: Effect of Specific Prognostic Markers on Survival and Development of a Prognostic Model. J Clin Oncol2015. 33 : 3766-3773.

7 Arulogun SO, Prince HM, Ng J et al. Long-term outcomes of patients with advanced-stage cutaneous T-cell lymphoma and large cell transformation. Blood 2008. $112: 3082-3087$. 
8 Salhany KE, Cousar JB, Greer JP et al. Transformation of cutaneous T cell lymphoma to large cell lymphoma. A clinicopathologic and immunologic study. Am J Pathol 1988. 132 : 265-277.

9 Vergier B, de Muret A, Beylot-Barry M et al. Transformation of mycosis fungoides: clinicopathological and prognostic features of 45 cases. French Study Group of Cutaneious Lymphomas. Blood 2000.95 : 2212-2218.

10 Vural S, Akay BN, Botsali A et al. Transformation of Mycosis Fungoides/Sezary Syndrome: Clinical Characteristics and Prognosis. Turk J Haematol 2018. 35 : 35-41.

11 Talpur R, Sui D, Gangar P et al. Retrospective Analysis of Prognostic Factors in 187 Cases of Transformed Mycosis Fungoides. Clin Lymphoma Myeloma Leuk 2016. 16 : 49-56.

12 Bekkenk MW, Geelen FA, van Voorst Vader PC et al. Primary and secondary cutaneous CD30(+) lymphoproliferative disorders: a report from the Dutch Cutaneous Lymphoma Group on the long-term follow-up data of 219 patients and guidelines for diagnosis and treatment. Blood2000. 95 : 3653-3661.

13 Kempf W, Pfaltz K, Vermeer MH et al. EORTC, ISCL, and USCLC consensus recommendations for the treatment of primary cutaneous CD30-positive lymphoproliferative disorders: lymphomatoid papulosis and primary cutaneous anaplastic large-cell lymphoma. Blood 2011.118 : 4024-4035.

14 Benner MF, Willemze R. Applicability and prognostic value of the new TNM classification system in 135 patients with primary cutaneous anaplastic large cell lymphoma. Arch Dermatol 2009. 145 : 1399-1404.

15 Kadin ME, Hughey LC, Wood GS. Large-cell transformation of mycosis fungoides-differential diagnosis with implications for clinical management: a consensus statement of the US Cutaneous Lymphoma Consortium. J Am Acad Dermatol 2014. 70 : 374-376.

16 Willemze R, Kadin ME, Kempf W, Paulli M. Primary cutaneous CD30+ T-cell lymphoproliferative disorders. In: WHO Classification of Skin Tumours (Elder DE, Massi D, Scolyer RA, Willemze R, eds), 4th edn. Lyon: International Agency for Research on Cancer. 2018; 236-239.

17 Suga H, Sugaya M, Sato S. C-C chemokine receptor type 3 expression in lymphomatoid papulosis, but not in mycosis fungoides lesions from the same patient. Clin Exp Dermatol 2012. 37 : 75-77.

18 Suga H, Sugaya M, Miyagaki T et al. Differential patterns of CXCR3, CCR3, and CCR10 expression in mycosis fungoides, Sezary syndrome and CD30 $(+)$ lymphoproliferative disorders: immunohistochemical study of 43 samples. J Dermatol Sci 2011. 64 : 142-144.

19 Yamaguchi T, Ohshima K, Karube $\mathrm{K}$ et al. Expression of chemokines and chemokine receptors in cutaneous CD30+ lymphoproliferative disorders. Br J Dermatol 2006. 154 : 904-909.

20 Lai PJ HY, Hsu JD, Wey SJ. Early stage mycosis fungoides with focal CD30-positive large cell transformation. In: Dermatologica Sin [Internet] , Vol. 31. Taipei Elsevier Taiwan LLC. 2013; 73-77.

21 Ohtani T, Kikuchi K, Koizumi H et al. A case of CD30+ large-cell transformation in a patient with unilesional patch-stage mycosis fungoides. Int J Dermatol 2009. 48 : 623-626.

22 Watchorn RE, Pawade J, Wachsmuth RC. Unilesional CD30+ mycosis fungoides with large cell transformation and spontaneous regression, masquerading as verruca vulgaris. Clin Exp Dermatol 2018.43 : 633-635.

23 Besch-Stokes JG, Costello CM, Bhullar PK et al. Regression of mycosis fungoides with large-cell transformation following skin biopsy.J Eur Acad Dermatol Venereol 2020. 34 : e82-e84.

\section{Figure Legends}

Fig. 1. Clinical manifestations at the first visit

a, b) Macroscopic findings. Multiple areas of erythema measuring 1-10 cm in diameter are evident. c) Histopathological findings of the erythema (hematoxylin-eosin stain, $\times 200$ ). Small-sized atypical lymphocyte- 
like hyperchromatic cells with haloes had infiltrated into the epidermis and upper dermis in a scattered manner.

\section{Fig. 2. Clinical manifestations during the course of the disease}

a) Macroscopic findings at two years after the first visit. Two ulcerative tumors are evident on MF patchlesions of the left chest.b) Histopathological findings of the tumor (hematoxylin-eosin stain, loupe image). Nodular infiltration of tumor cells is evident in the dermis and subcutis. c) Histopathological findings of the tumor (hematoxylin-eosin stain, $\times 400$ ). Some nests consist of anaplastic large cells. d) Histopathological findings of the tumor (hematoxylin-eosin stain, $\times 400$ ). Small-sized atypical lymphocyte-like hyperchromatic cells have proliferated in the tumor. e)Immunohistochemical examination of the tumor using anti-CD30 antibody (Roche, Basel, Switzerland) (loupe image). Anti-CD30 antibodies are reactive to nearly half of the cells in the tumor. f)Immunohistochemical examination using anti-CD30 antibody $(\times 400)$. Anti-CD30 antibodies are reactive to anaplastic large cells. g)Immunohistochemical examination using anti-CD30 antibody (×400). Anti-CD30 antibodies are not reactive to small atypical cells.h) Immunohistochemical examination using anti-CXCR3 antibody (R\&D systems, Minneapolis, MN) $(\times 100)$. Anti-CXCR3 antibodies are reactive to anaplastic large cells. i) Immunohistochemical examination using anti-CCR3 antibody (R\&D systems) $(\times 100)$. Anti-CCR3 antibodies are not reactive to anaplastic large cells. $\mathbf{j})$ Macroscopic findings at 3 months after the initial appearance of the tumors. The tumors regressed spontaneously, leaving scars.
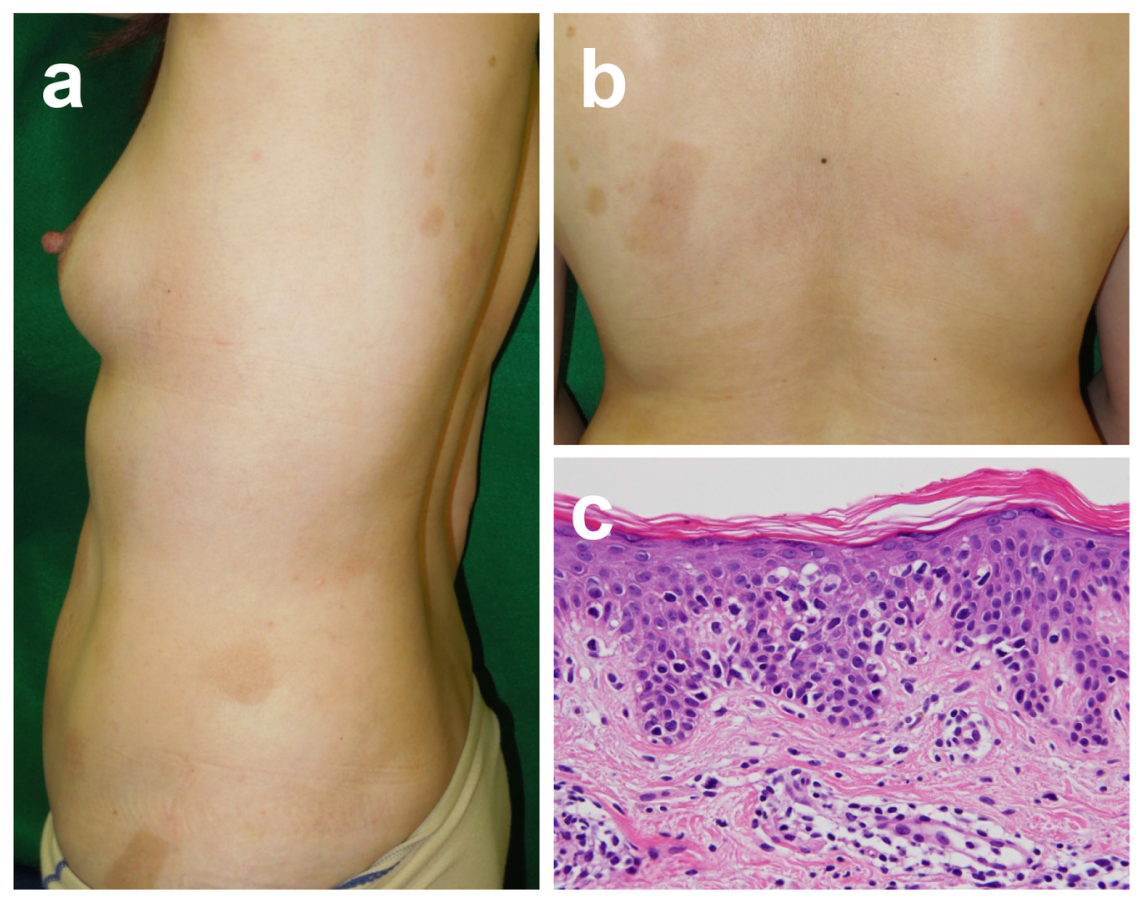

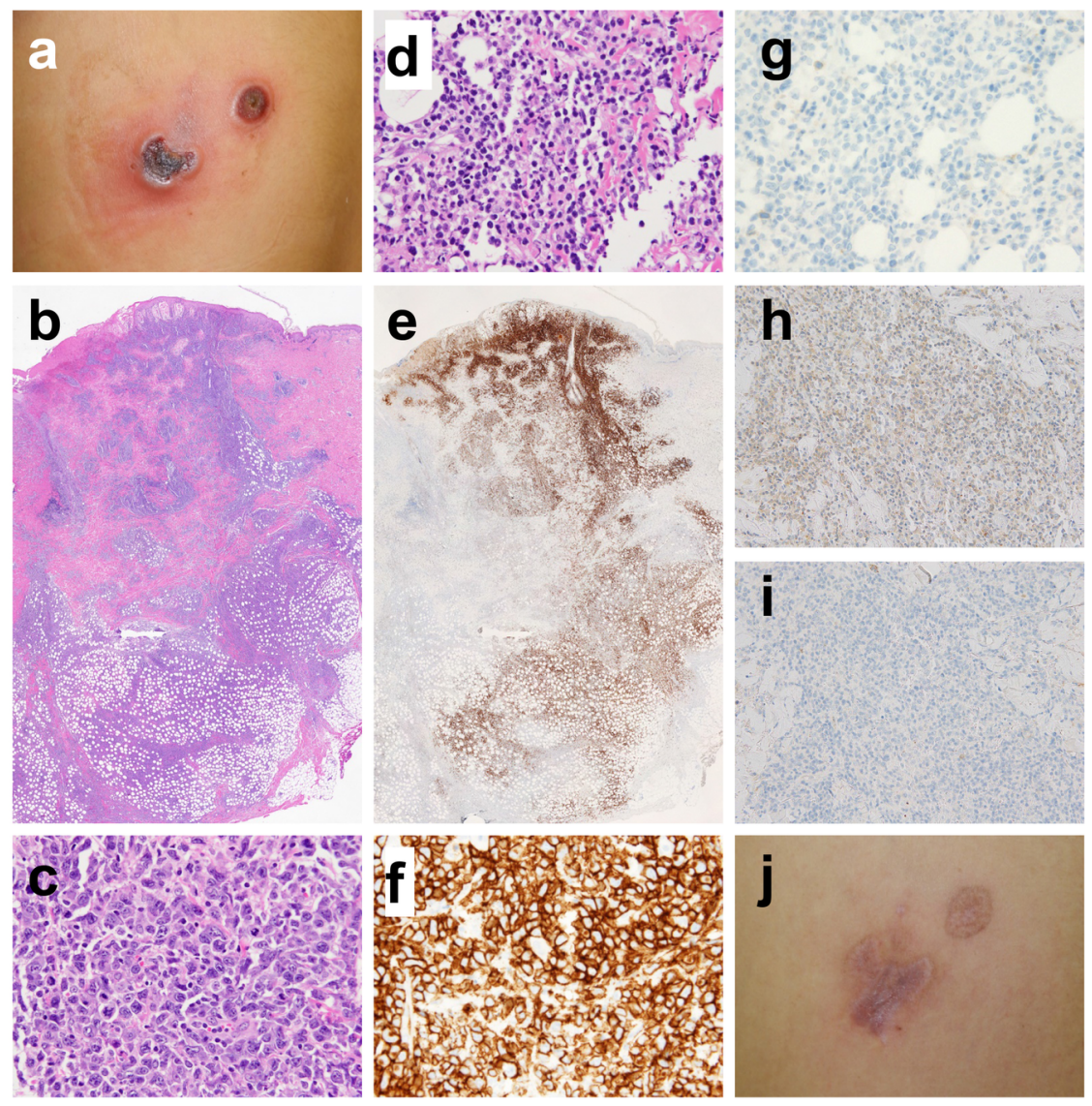